\title{
Estimating Young's Modulus of Materials by a New Three-Point Bending Method
}

\author{
Xiaohu Zeng, ${ }^{1}$ Shifeng Wen, ${ }^{1}$ Mingxi Li, ${ }^{1}$ and Gongnan Xie ${ }^{2}$ \\ ${ }^{1}$ School of Mechanics and Civil Engineering \& Architecture, Northwestern Polytechnical University, Xi'an, Shaanxi 710129, China \\ ${ }^{2}$ School of Mechanical Engineering, Northwestern Polytechnical University, Xian, Shaanxi 710072, China \\ Correspondence should be addressed to Xiaohu Zeng; zengxiaohu@mail.nwpu.edu.cn
}

Received 10 January 2014; Revised 6 May 2014; Accepted 10 June 2014; Published 17 July 2014

Academic Editor: Tao Zhang

Copyright (c) 2014 Xiaohu Zeng et al. This is an open access article distributed under the Creative Commons Attribution License, which permits unrestricted use, distribution, and reproduction in any medium, provided the original work is properly cited.

\begin{abstract}
A new test method based on the three-point bending test is put forward to measure Young's modulus of materials. The simplified mechanical model is established to make theoretical derivation. This method has not only the advantages of simple specimen preparation and convenient loading device, but also higher precision than the traditional three-point bending method. The method is adopted to obtain Young's modulus of the aluminum alloy 2024. The feasibility of the method has been demonstrated by comparisons with the corresponding results obtained from the finite element method and experiment method. And the influence of contact friction on the test accuracy is analyzed.
\end{abstract}

\section{Introduction}

Ultrahigh temperature materials have been used in many fields to protect structural components from the intrinsic high temperatures, for example, on cooled gas turbines blades or vanes and the vehicle nose-tip [1]; therefore how to obtain material properties accurately under the ultrahigh temperature environment is the urgent problem to be solved in current research field [2-6].

There are some methods to obtain the mechanical properties of ultrahigh temperature materials especially the film/substrate system (the thermal barrier coating material) at present, such as tensile test, indentation test, and tympanic membrane test. However, all these methods are limited by the temperature and sample processing. The tensile test has a certain requirements of number and size on the sample, and the requirements cannot be met in some cases. First, it invariably runs into problems such as fixture oxidation, strength reduction, and processing difficulties due to high temperature in the fixture design process. Second, the thermal barrier coating (TBC) systems cannot be processed into standard samples. Third, the method is not suitable for ultrahigh temperature environment $[7,8]$. Therefore, the indentation test has been applied to some extent. The indentation test has some advantages. First, it is local and nondestructive. Second, the test data can be measured directly in the stress concentration location. Zorzi and Perottoni studied Young's modulus by indentation test in 2013 [9]. However, this method still has some problems. For example, its precision in ultrahigh temperature environment is hard to control because of the influence of thermal drift produced in the ultrahigh temperature testing process [10]. And the mechanical properties of materials obtained under high pressure stress do not have a good agreement with the results under tensile stresses. The bulge test is designed to determine the mechanical properties of thin film/substrate materials, but there is no report on application of the tympanic membrane test in ultrahigh temperature environment.

In the paper, a new test method is put forward to make up for lack of the above tests, namely, simple bending test method. The method has not only the advantages of simple specimen preparation and convenient loading device of the traditional three-point bending test, but also higher precision because the location of maximum stress and maximum deflection is not in the same place. For the traditional threepoint and four-point bending test, the bending deflection 


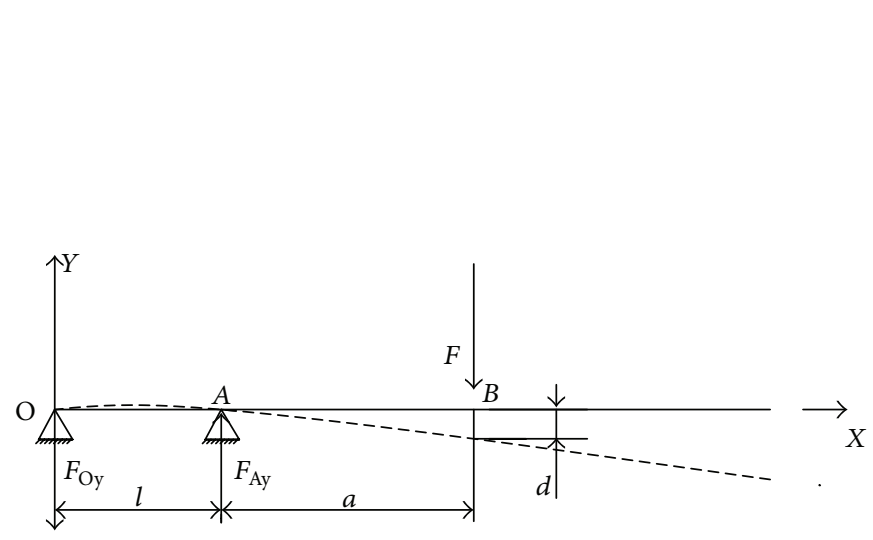

(a)

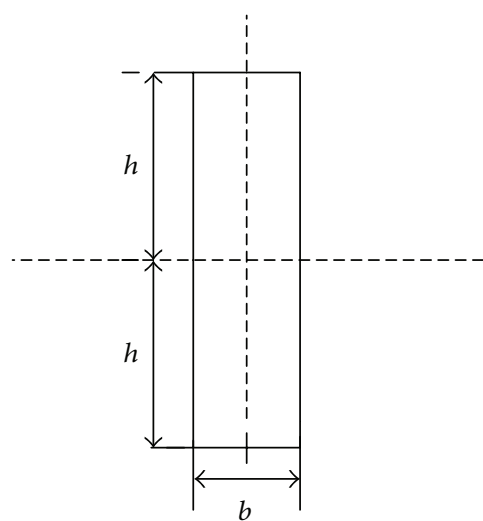

(b)

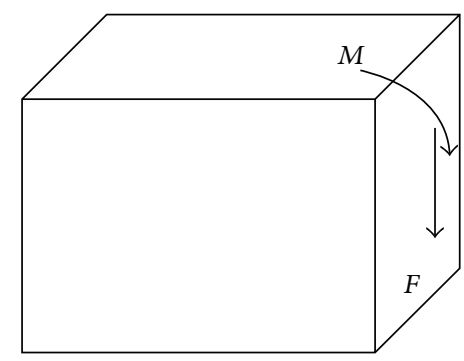

(c)

FIGURE 1: The simplified geometry model of test device to measure Young's modulus of materials. (a) Schematic diagram of geometry; (b) schematic diagram of the cross section of the sample; (c) force analysis diagram of the cross section of the sample.

and failure locations of the sample both occur in the middle position, as well as the contact position of indenter and measuring deflection data position, so the sample's bending deformation will greatly influence the accuracy of deflection [11]. The emphasis of the paper is to clarify the basic theory of adopting the new method to determine the Young's modulus of single phase materials. The Young's modulus is a basic mechanical parameter to characterize elastic deformation properties of solid materials and also an important basis for selecting mechanical components in engineering design. The test principle is described in the following part. And the feasibility of the method has been demonstrated by comparisons with the corresponding results obtained from the finite element method and experiment method. It can provide a theoretical foundation for applying the method to determine the elastic modulus of ultrahigh temperature materials.

\section{Description of the Test Principle}

The simplified geometry model of new test device is shown in Figure 1. Taking the point $O$ as the origin of coordinates, the coordinate system is established.

The support reactions are obtained by equilibrium conditions $\sum M_{O}=0$ and $\sum M_{A}=0$; that is,

$$
F_{\mathrm{O} y}=-\frac{F a}{l} \quad F_{A y}=\frac{F(l+a)}{l},
$$

where $F_{\mathrm{O} y}$ and $F_{A y}$ are the support reactions of $O$ and $A$, respectively, $F$ is the applying load, $l$ is the distance between two supports, and $a$ is the distance between the loading point and the support $A$. Then the shear forces and bending moment equations of the sample can be obtained, as follows:

$$
\begin{gathered}
F_{s}\left(x_{1}\right)=-\frac{F a}{l} \quad M\left(x_{1}\right)=-\frac{F a}{l} x_{1} \quad\left(0 \leq x_{1} \leq l\right) \\
F_{s}\left(x_{2}\right)=F \quad M\left(x_{2}\right)=F\left(x_{2}-(l+a)\right) \\
\left(l \leq x_{2} \leq l+a\right),
\end{gathered}
$$

where $F_{s}\left(x_{1}\right)$ and $F_{s}\left(x_{2}\right)$ are the shear forces of $O A$ and $A B$, respectively, and $M\left(x_{1}\right)$ and $M\left(x_{2}\right)$ are bending moments of $O A$ and $A B$, respectively. From the theory of Mechanics of Materials [12], the equation of bending deformation is obtained:

$$
\frac{1}{\rho(x)}=\frac{M(x)}{E I}
$$

where $\rho$ is the curvature radius of deflection curve, $E$ is the Young's modulus of the sample, and $I$ is the inertia moment of $z$-axis. Because the cross section height is far smaller than the span, the influence on deformation of the shear stress is very small and can be ignored. Equation (3) can be rewritten as

$$
\frac{1}{\rho(x)}=\frac{M(x)}{E I}
$$




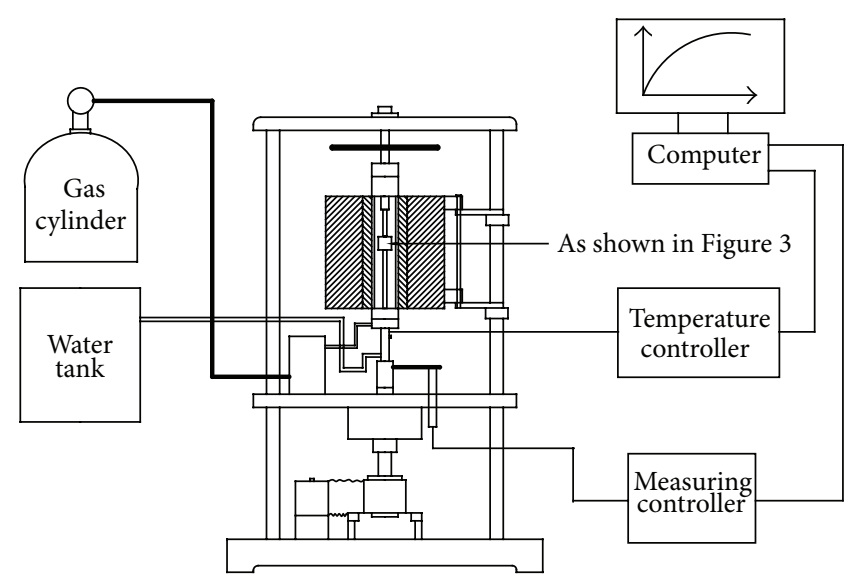

FIGURE 2: Schematic diagram of the test system.

From the theory of Higher Mathematics, the following equation can be obtained:

$$
\frac{1}{\rho}=\frac{d^{2} y / d x^{2}}{\sqrt{\left[1+(d y / d x)^{2}\right]^{3}}} .
$$

The deflection curve is nearly flat in the elastic deformation stage, so the value of $d y / d x$ is very small. The following equation is obtained:

$$
\begin{gathered}
\frac{1}{\rho} \approx \frac{d^{2} y}{d x^{2}}, \\
\therefore \frac{d^{2} y}{d x^{2}}=\frac{M}{E I} .
\end{gathered}
$$

Then the following approximate differential equations of the deflection curve can be obtained from (2) and (7):

$$
\begin{gathered}
E I \frac{d^{2} y_{1}}{d x_{1}^{2}}=-\frac{F a}{l} x_{1}, \\
E I \frac{d y_{1}}{d x_{1}}=-\frac{F a}{2 l} x_{1}^{2}+C_{1}, \\
E I y_{1}=-\frac{F a}{6 l} x_{1}^{3}+C_{1} x_{1}+D_{1}, \\
E I \frac{d^{2} y_{2}}{d x_{2}^{2}}=F\left(x_{2}-(l+a)\right), \\
E I \frac{d y_{2}}{d x_{2}}=\frac{F}{2}\left(x_{2}-(l+a)\right)^{2}+C_{2}, \\
E I y_{2}=\frac{F}{6}\left(x_{2}-(l+a)\right)^{3}+C_{2} x_{2}+D_{2},
\end{gathered}
$$

where $y_{1}$ and $y_{2}$ are the deflections of $O A$ and $A B$, respectively and $C_{1}, C_{2}, D_{1}$, and $D_{2}$ are unknown coefficients. Consider

$$
I=\frac{b(2 h)^{3}}{12}=\frac{2 b h^{3}}{3} .
$$

The boundary conditions and continuity and smoothness conditions are described as follows:

$$
\begin{gathered}
y_{1}(0)=0 \quad\left(x_{1}=0\right) \\
\frac{d y_{1}}{d x_{1}}=\frac{d y_{2}}{d x_{2}} \quad y_{1}=y_{2}=0 \quad\left(x_{1}=x_{2}=l\right) .
\end{gathered}
$$

Substituting (15) into (9), (10), (12), and (13), the following equations are obtained:

$$
\begin{gathered}
C_{1}=\frac{F}{6} l a \quad D_{1}=0 \\
C_{2}=-\frac{F}{6}\left(2 l a+3 a^{2}\right) \quad D_{2}=\frac{F}{6}\left(a^{3}+2 a l^{2}+3 l a^{2}\right) \\
E I y_{2}=\frac{F}{6}\left(x_{2}-(l+a)\right)^{3}-\frac{F}{6}\left(2 l a+3 a^{2}\right) x_{2} \\
+\frac{F}{6}\left(a^{3}+3 l a^{2}+2 a l^{2}\right) \\
\therefore E I y_{2}=-\frac{F}{3}\left(a^{3}+a^{2} l\right) \quad\left(x_{2}=l+a\right) .
\end{gathered}
$$

As can be seen from the above equation, the bending deflection of $B$ is proportional to the applying load. From (19), the following equation is obtained:

$$
E=-\frac{F}{3 I y_{2}}\left(a^{3}+a^{2} l\right) .
$$

Therefore, as long as the ratio of applying load and bending deflection in the elastic deformation stage is obtained, Young's modulus of the sample can be calculated.

\section{The Test Device and Materials}

The new test system of determining Young's modulus proposed in the paper is shown in Figure 2. The test system is refitted by INSTRON8871 electrohydraulic servo fatigue 

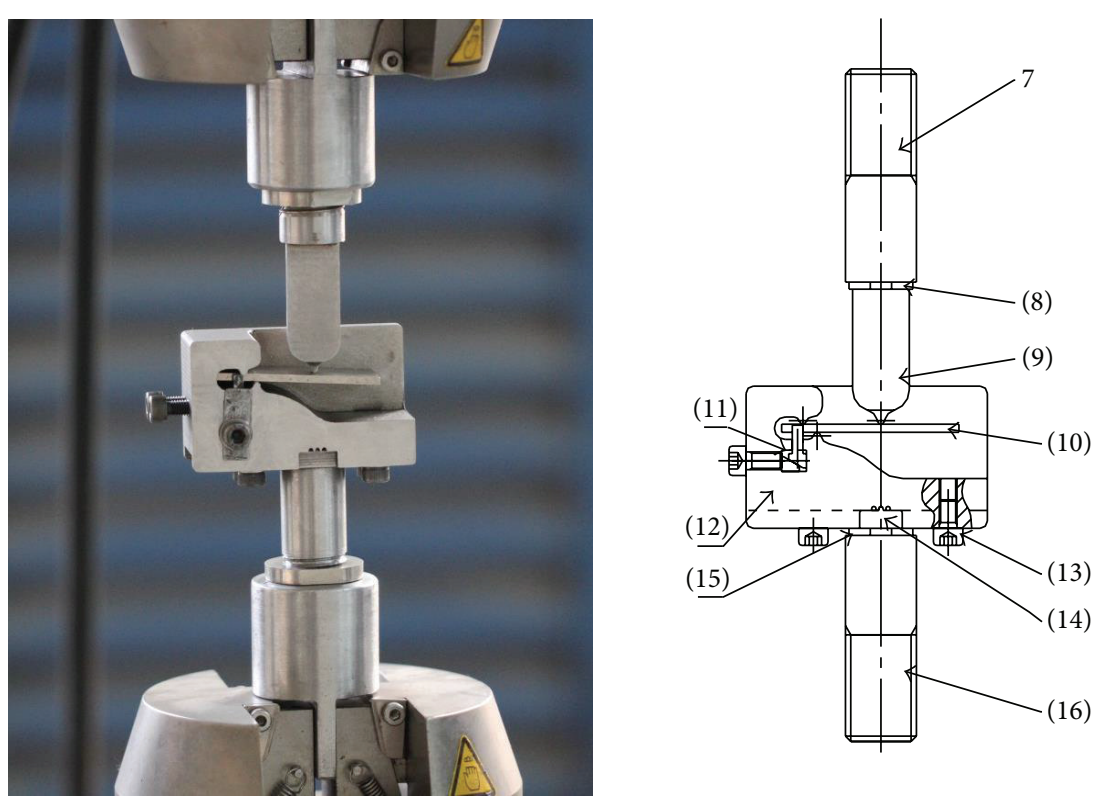

FIGURE 3: Schematic diagram of the test device.

TABLE 1: The composition and content of aluminum alloy 2024 (wt.\%).

\begin{tabular}{|c|c|c|c|c|c|c|c|c|c|c|}
\hline \multirow{2}{*}{$\mathrm{Si}$} & \multirow{2}{*}{$\mathrm{Fe}$} & \multirow{2}{*}{$\mathrm{Cu}$} & \multirow{2}{*}{$\mathrm{Mn}$} & \multirow{2}{*}{$\mathrm{Mg}$} & \multirow{2}{*}{$\mathrm{Cr}$} & \multirow{2}{*}{$\mathrm{Zn}$} & \multirow{2}{*}{$\mathrm{Ti}$} & \multicolumn{2}{|c|}{ Others } & \multirow{2}{*}{$\mathrm{Al}$} \\
\hline & & & & & & & & Single & Total & \\
\hline 0.50 & 0.50 & $3.8 \sim 4.9$ & $0.30 \sim 0.9$ & $1.2 \sim 1.8$ & 0.10 & 0.25 & 0.15 & 0.05 & 0.15 & allowance \\
\hline
\end{tabular}

testing machine. The system is equipped with a temperature control system and a cooling system, and it can create a high temperature environment above $800^{\circ} \mathrm{C}$. The displacement meter comes with INSTRON8871 electrohydraulic servo fatigue testing machine. Its accuracy is $\pm 0.1 \%$ which can meet the requirements of the test. The fatigue loading system of ISTRON8871 fatigue machine is adopted to apply loads.

The test device adopted in the paper is shown in Figure 3. One end of the above transitional connection rod 7 is connected directly to the electrohydraulic servo fatigue testing machine. And the other end is connected with indenter 9 by bolt connection. The two nuts 8 and 15 are used to fasten indenter 9 and the lower transitional connection rod 16. The fixing device 12 connected to the lower transitional connection rod 16 by bolt connection is used to fix sample 10 . And there are removable grooves 14 below the fixing device. It can change the contact position of indenter and sample to ensure the adequacy of test results.

The material of sample is aluminum alloy 2024. Its Young's modulus $\left(E_{0}=71 \mathrm{GPa}\right)$ is known by consulting document. And its composition and content are shown in Table 1 [13]. The sample is in a rectangle shape with length of $50 \mathrm{~mm}$, width of $20 \mathrm{~mm}$, and height of $2 \mathrm{~mm}$. The material of indenter is cast nickel-base superalloy K403. The deformation of the indenter relative to the bending deflection of the sample is too small, so its deformation is not taken into consideration during the test. As the influence of contact friction between the indenter and sample on bending deflection is very small, it is also ignored.

\section{The Finite Element Model}

According to the characteristics of the new test device, the finite element model can be simplified as shown in Figure 4. The finite element software ABAQUS [14] is adopted to carry on the numerical simulation in the paper. In order to accurately simulate the stress and deformation gradient in the contact region, the grids of contact region are refined. As the deformation of the indenter relative to the bending deflection of the sample can be ignored, the indenter and supports are simplified as a rigid body without deformation in the finite element analysis in order to simplify the calculation. And the influence of friction is not taken into consideration in the process of numerical simulation. The research object in this paper is Young's modulus of materials, so the ambient temperature is not taken into consideration temporarily. The boundary condition applied to the model is that the two supports are fixed, the indenter is limited to move along the $Y$ direction only, and the initial state of the sample is in horizontality. The load is applied on the indenter.

\section{Results and Discussions}

The load spectrum adopted in numerical simulation is a monotonically increasing spectrum, as shown in Figure 5. 


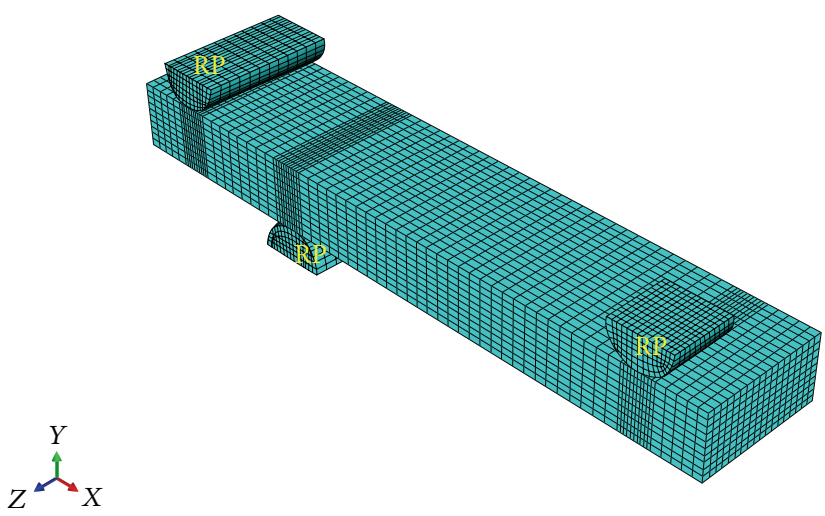

(a)

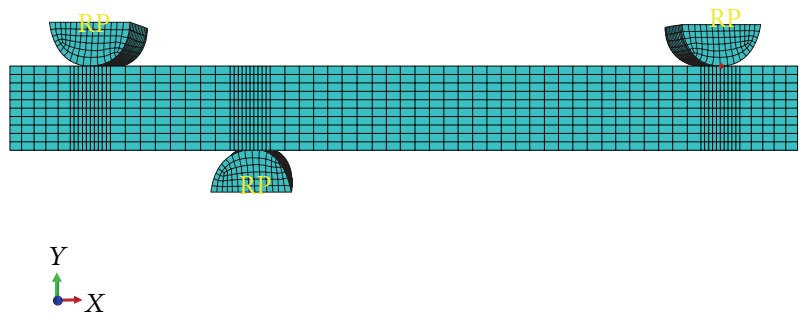

(b)

FiguRE 4: The finite element model for numerical calculations performed in the present study. (a) Model of indentation fatigue; (b) the reference point is highlighted.

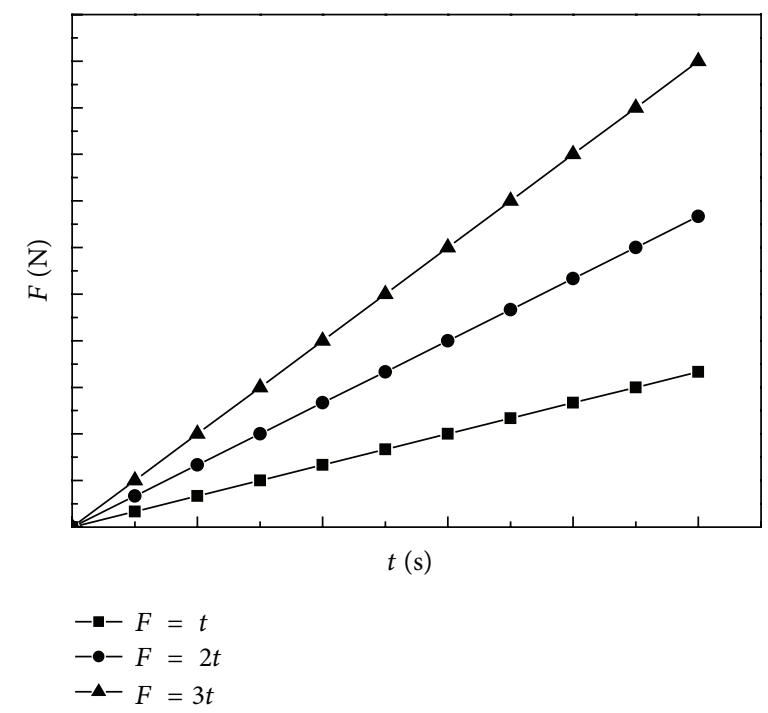

FIGURE 5: The load spectrum adopted in numerical simulation.

Figure 6 shows the relationship between the bending deflection and the applying load of the reference point of the sample. From the figure we can see that the slope of the load spectrum has no effect on the numerical simulation results; that is to say, the load's increase speed with time has no effect on the bending deflection of the sample. And the deformation of the sample has two obvious stages. (1) The first stage is stage $\mathrm{AB}$ : the stage where the bending deflection of the reference point monotonically increases with the applying load, that is, the elastic deformation stage. (2) The second stage is stage BC: the stage where the bending deflection of the reference point rapidly increases with the applying load, that is, the plastic deformation stage. From the second section we know that as long as the ratio of applying load and bending deflection in the elastic deformation stage is obtained, Young's modulus of the sample can be calculated. Therefore, the focus of this paper is the elastic deformation stage, that is, stage $A B$ as shown in the figure. Young's modulus of the sample in finite element simulation is calculated. Consider $E_{f}=70.24 \mathrm{GPa}$. This result has a good agreement with the Young's modulus obtained by consulting document.

\section{Experiment Results and Discussions}

The load spectrum adopted in the test is a monotonically increasing spectrum $(F=t)$ in the same as the numerical simulation. It is applied to the sample by the loading system of ISTRON8871 fatigue machine. The test data are set to record every $0.02 \mathrm{~s}$. All the tests are carried out at room temperature. The above load spectrum is applied on the sample to test three times without difference. The relationship between the bending deflection and the applying load of the sample is shown in Figure 7.

From Figure 7, we can see that the deformation of the sample has also two obvious stages: (1) stage $A B$, 


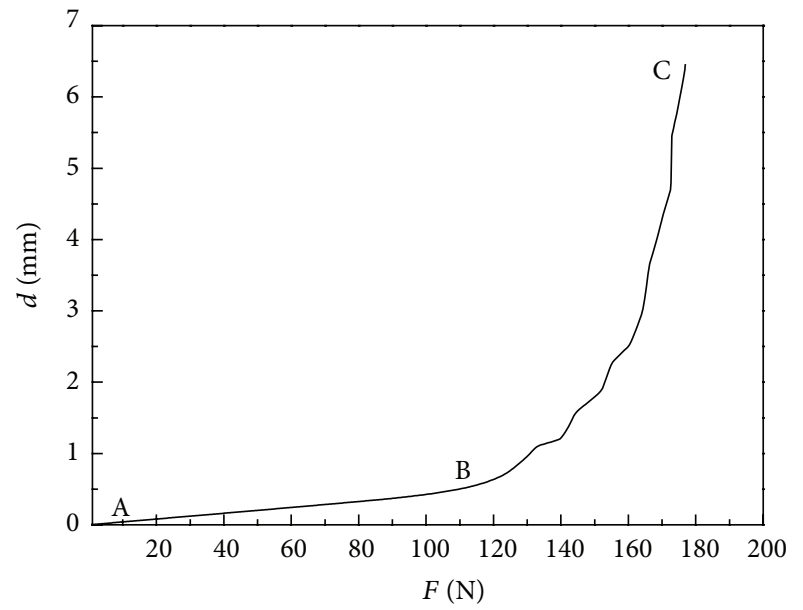

(a)

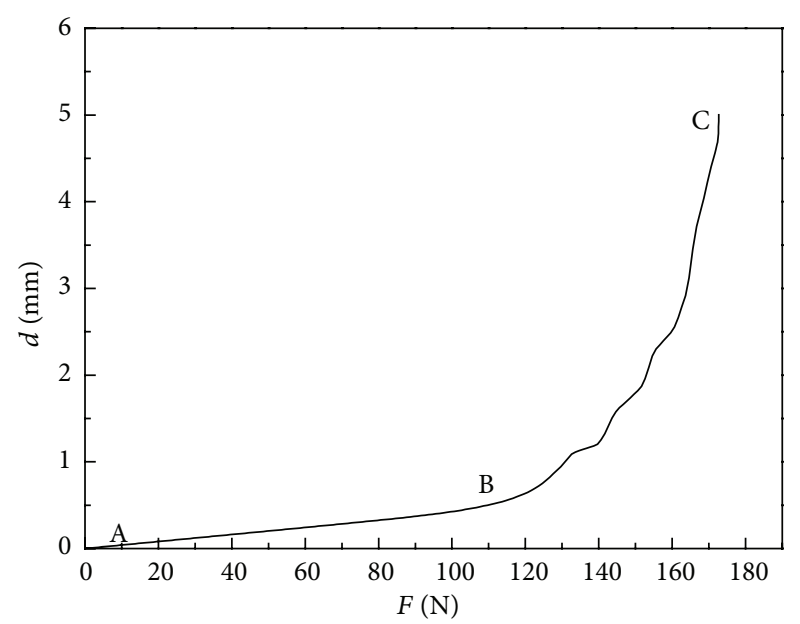

(b)

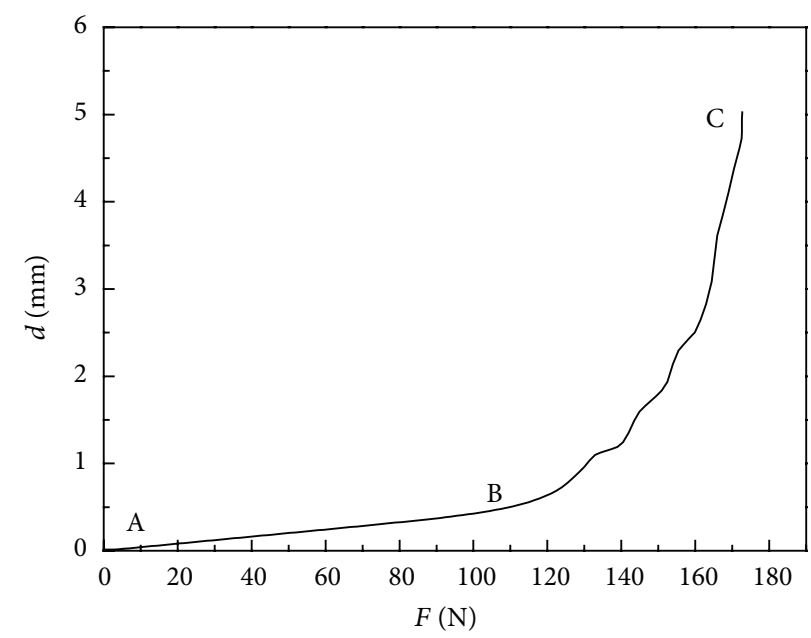

(c)

FiguRE 6: The results of finite element simulation. (a) The relationship between the bending deflection and the applying load of the reference point. The load spectrum is $F=t$; (b) the relationship between the bending deflection and the applying load of the reference point. The load spectrum is $F=2 t$; (c) the relationship between the bending deflection and the applying load of the reference point. The load spectrum is $F=3 t$.

TABLE 2: Test data processing.

\begin{tabular}{lc}
\hline Sample number & Young's modulus \\
\hline 1 & $E_{1}=72.6 \mathrm{GPa}$ \\
2 & $E_{2}=71.8 \mathrm{GPa}$ \\
3 & $E_{3}=73.5 \mathrm{GPa}$ \\
\hline
\end{tabular}

the stage where the bending deflection of the reference point monotonically increases with the applying load, that is, the elastic deformation stage; (2) stage $\mathrm{BC}$, the stage where the bending deflection of the reference point rapidly increases with the applying load, that is, the plastic deformation stage. The focus of this paper is stage AB. The test data processing is shown in Table 2. The method adopted in calculation process is linear regression method. The test results show that Young's modulus of materials obtained by the new test method proposed in the paper corresponds to the Young's modulus obtained by consulting document well. And the feasibility of the method has been demonstrated.

\section{Error Analysis}

The test error is calculated as $e=\left(E_{t}-E_{0}\right) / E_{0}=2.3 \%$. The factors that produce the error may be that the influences of deformation of the indenter and contact friction are not taken into consideration. And the influence of contact friction is studied as follows.

Figure 8 shows the relationship between the bending deflection and the applying load of the reference point of the sample under different friction forces by finite element simulation. The Young's modulus is calculated, as shown in Table 3. From the figure, we can see that the contact friction 


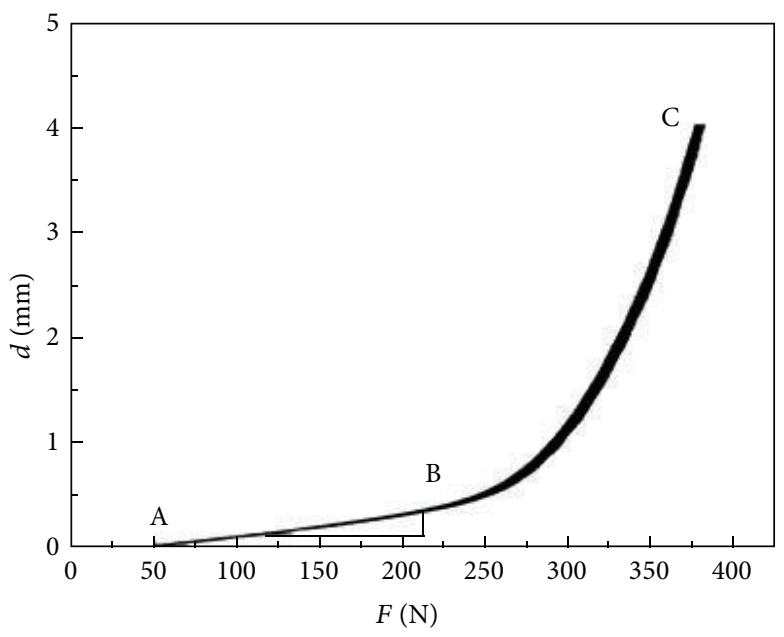

(a)

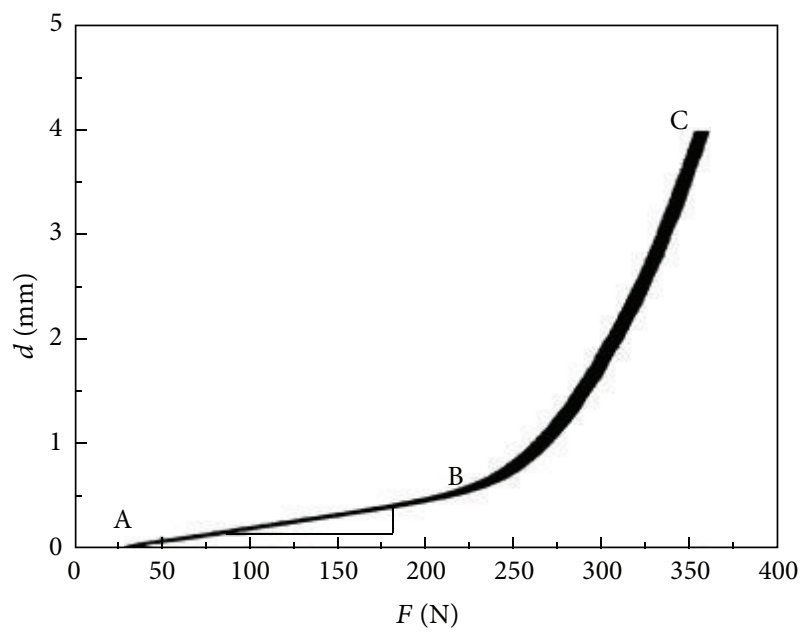

(b)

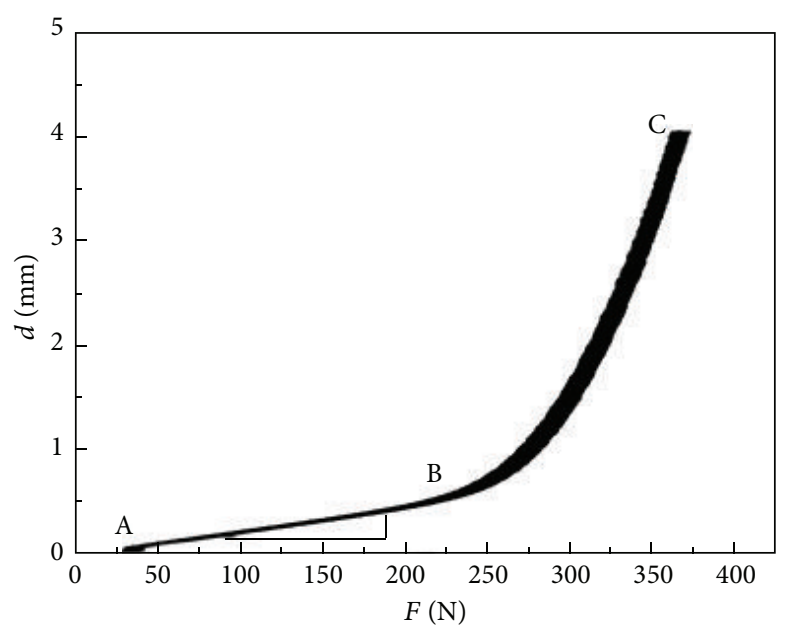

(c)

Figure 7: The relationship between the bending deflection $(d)$ and the applying load $(F)$ of the sample. (a) The $d$ - $F$ curve of sample 1; (b) the $d-F$ curve of sample 2 ; (c) the $d-F$ curve of sample 3 .

TABLE 3: The calculation results.

\begin{tabular}{lc}
\hline Contact friction coefficient & Young's modulus \\
\hline 0 & $70.24 \mathrm{GPa}$ \\
0.25 & $75.1 \mathrm{GPa}$ \\
0.5 & $79.3 \mathrm{GPa}$ \\
\hline
\end{tabular}

has influence on determination of Young's modulus and the bigger contact friction coefficient is, the greater Young's modulus will be. The bigger contact friction coefficient will cause bigger shear stress to prevent the sample continually deforming, so the bending deflection will be smaller and Young's modulus will be greater.

\section{Concluding Remarks}

In the paper, a new test method and test device based on a new three-point bending test are put forward to measure Young's modulus of materials, and the main results are summarized as follows.

(1) The new method has advantages of simple principle, convenient operation, and wide field of application. The feasibility of the test method and test device has been demonstrated through finite element simulation and test on aluminum alloy 2024

(2) The contact friction has influence on determination of Young's modulus of materials and the bigger contact friction coefficient is, the greater Young's modulus will be.

\section{Conflict of Interests}

The authors declare that there is no conflict of interests regarding the publication of this paper. 


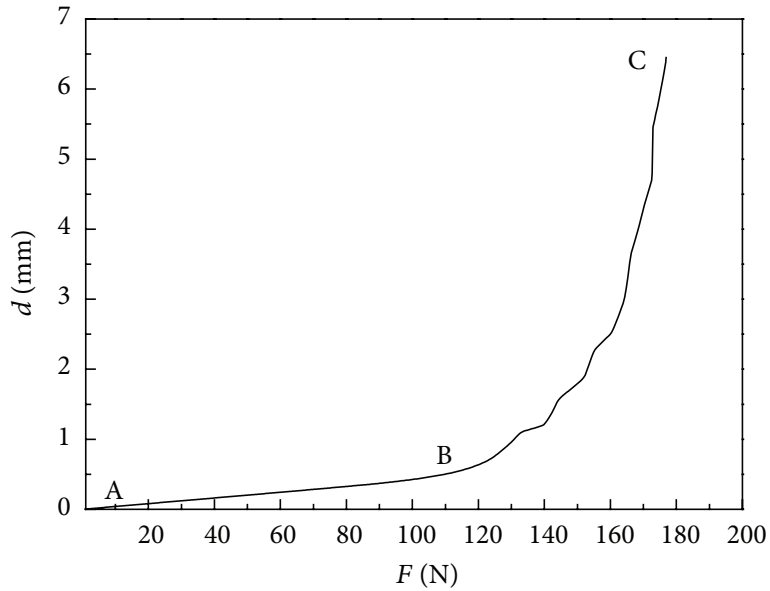

(a)

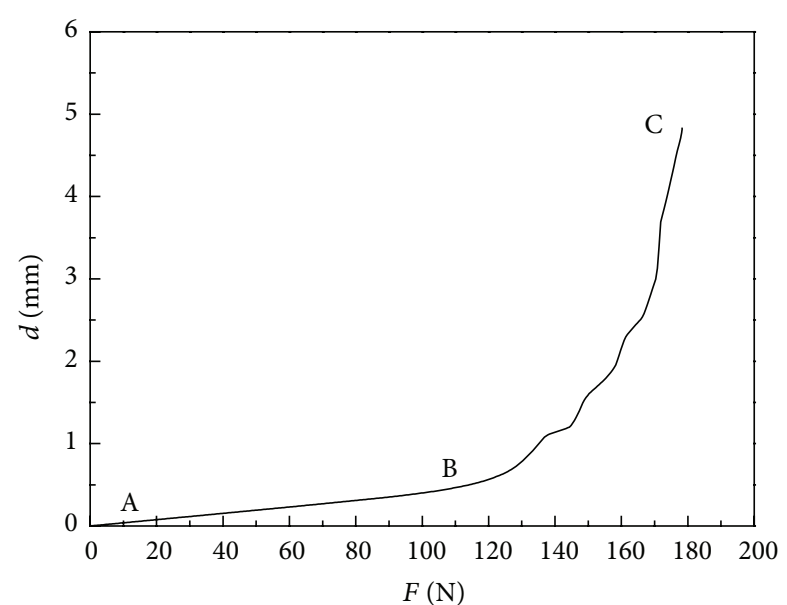

(b)

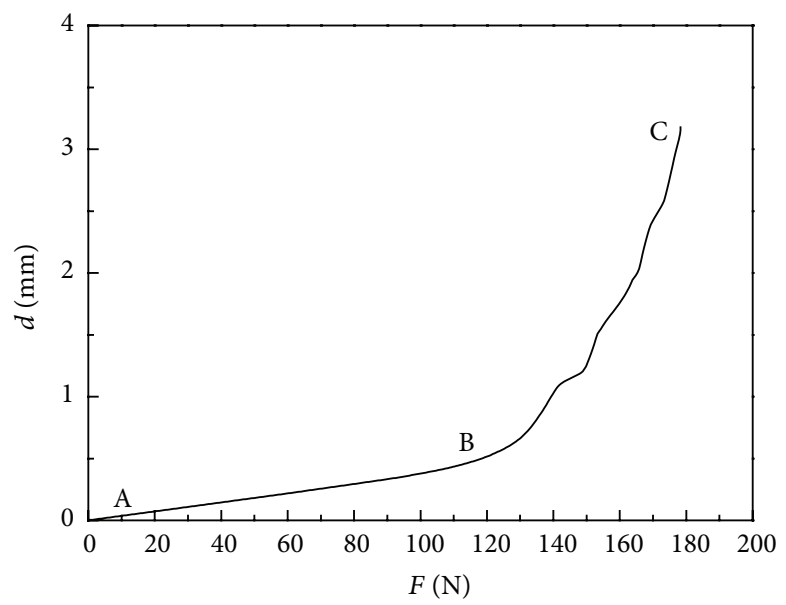

(c)

Figure 8: The relationship between the bending deflection $(d)$ and the applying load $(F)$ under different friction forces. (a) The contact friction coefficient is 0 . (b) The contact friction coefficient is 0.25 . (c) The contact friction coefficient is 0.5 .

\section{Acknowledgments}

This research is supported by Provincial Natural Science Foundation research project of Shaanxi (2014JQ1005), Aeronautical Science Foundation of China (2012ZD53053), Aerospace Technology Support Fund of China (2013-HTXGD), and Specialized Research Fund for the Doctoral Program of Higher Education of China (20126102120034).

\section{References}

[1] B. P. Bewlay, M. R. Jackson, J. C. Zhao, P. R. Subramanian, M. G. Mendiratta, and J. J. Lewandowski, "Ultrahigh-temperature Nb-silicide-based composites," MRS Bulletin, vol. 28, no. 9, pp. 646-653, 2003.

[2] T. Billot, P. Villechaise, M. Jouiad, and J. Mendez, "Creep-fatigue behavior at high temperature of a UDIMET 720 nickel-base superalloy," International Journal of Fatigue, vol. 32, no. 5, pp. 824-829, 2010.

[3] J. Codrington, P. Nguyen, S. Y. Ho, and A. Kotousov, "Induction heating apparatus for high temperature testing of thermo- mechanical properties," Applied Thermal Engineering, vol. 29, no. $14-15$, pp. 2783-2789, 2009.

[4] P. F. Giroux, F. Dalle, M. Sauzay et al., "Influence of strain rate on P92 microstructural stability during fatigue tests at high temperature," Procedia Engineering, vol. 2, no. 1, pp. 2141-2150, 2010.

[5] C. Courcier, V. Maurel, L. Rémy, S. Quilici, I. Rouzou, and A. Phelippeau, "Interfacial damage based life model for EB-PVD thermal barrier coating," Surface and Coatings Technology, vol. 205, no. 13-14, pp. 3763-3773, 2011.

[6] Y. Furuya, K. Kobayashi, M. Hayakawa, M. Sakamoto, Y. Koizumi, and H. Harada, "High-temperature ultrasonic fatigue testing of single-crystal superalloys," Materials Letters, vol. 69, pp. 1-3, 2012.

[7] R. L. Edwards, G. Coles, and W. N. Sharpe Jr., "Comparison of tensile and bulge tests for thin-film silicon nitride," Experimental Mechanics, vol. 44, no. 1, pp. 49-54, 2004.

[8] O. M. Abdelhadi, L. Ladani, and J. Razmi, "Fracture toughness of bonds using interfacial stresses in four-point bending test," Mechanics of Materials, vol. 43, no. 12, pp. 885-900, 2011. 
[9] J. E. Zorzi and C. A. Perottoni, "Estimating Young's modulus and Poisson's ratio by instrumented indentation test," Materials Science and Engineering A, vol. 574, pp. 25-30, 2013.

[10] J. M. Kranenburg, C. A. Tweedie, K. J. van Vliet, and U. S. Schubert, "Challenges and progress in high-throughput screening of polymer mechanical properties by indentation," Advanced Materials, vol. 21, no. 35, pp. 3551-3561, 2009.

[11] H. Ivankovic, E. Tkalcec, R. Rein, and H. Schmidt, "Microstructure and high temperature 4-point bending creep of sol-gel derived mullite ceramics," Journal of the European Ceramic Society, vol. 26, no. 9, pp. 1637-1646, 2006.

[12] F. P. Beer and E. R. Johnston Jr., Mechanics of Materials, McGraw-Hill, New York, NY, USA, 1992.

[13] W. F. Brown Jr., H. Mindin, and C. Y. Ho, Aerospace Structural Metals Handbook, vol. 3, CINDAS/Purdue University, Weat Latayette, IN, USA, 1994.

[14] HKS, ABAQUS User's Manual, version 6.2. 

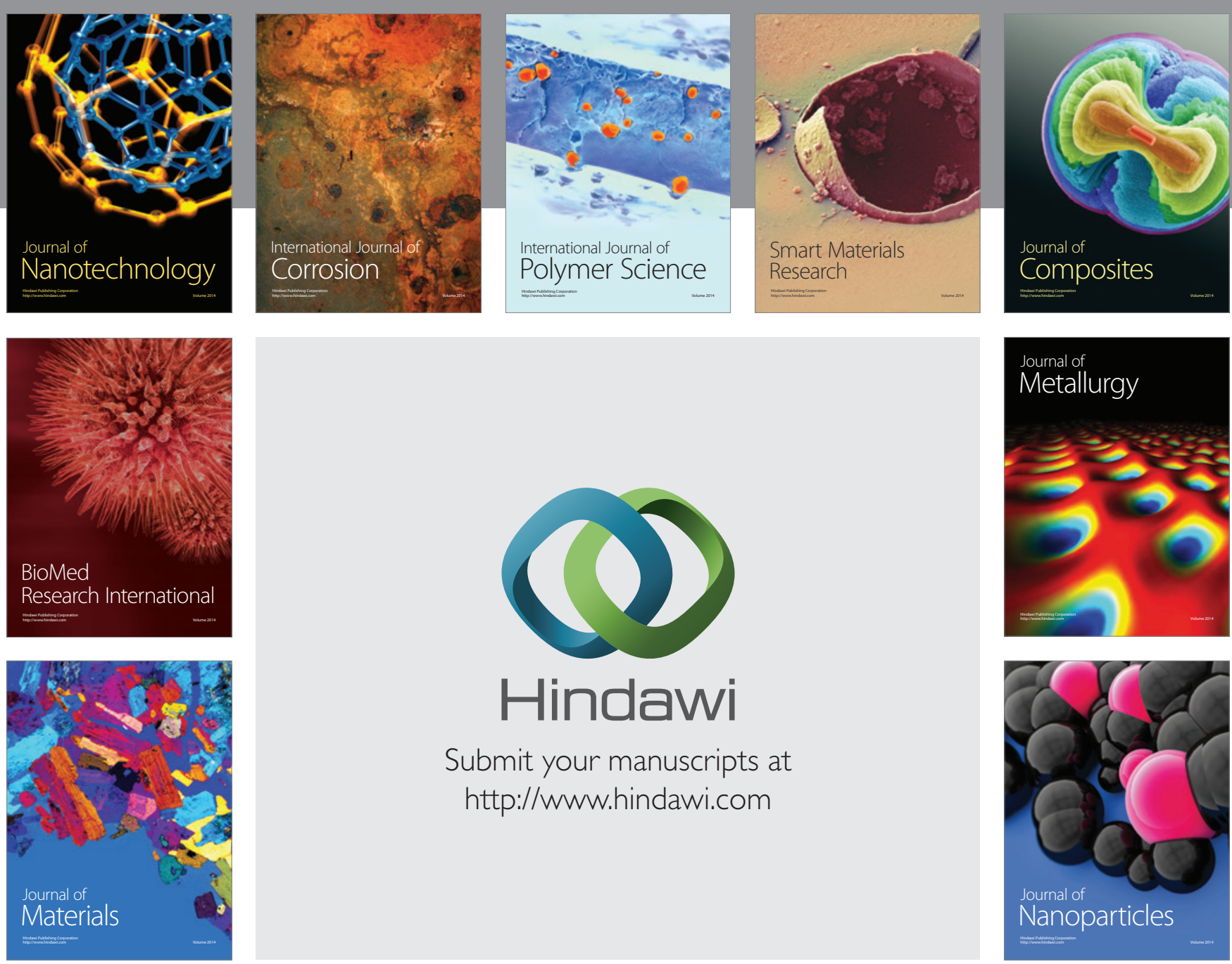

Submit your manuscripts at http://www.hindawi.com
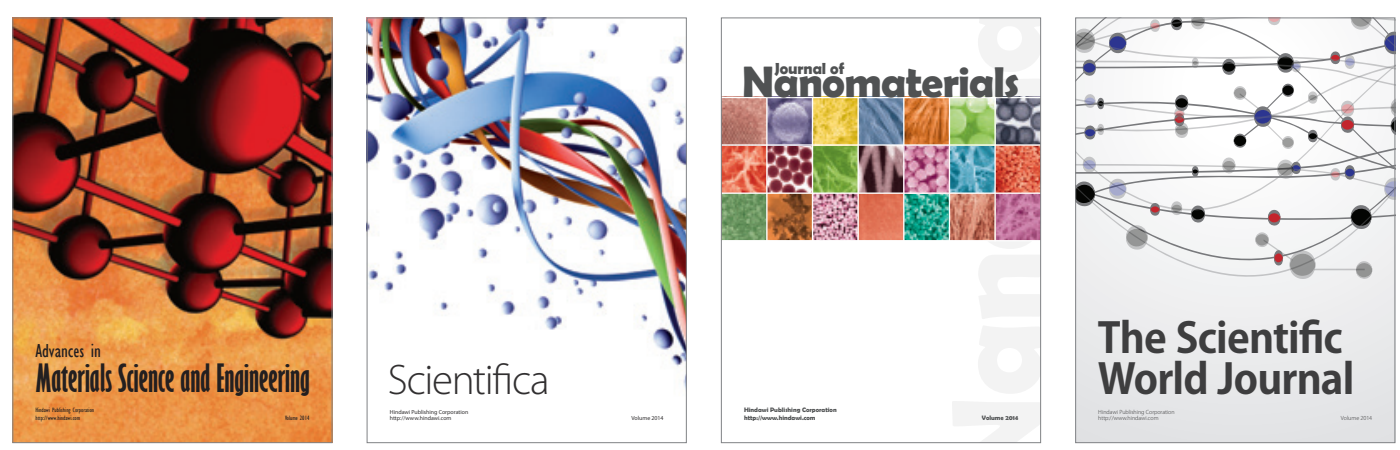

\section{The Scientific World Journal}
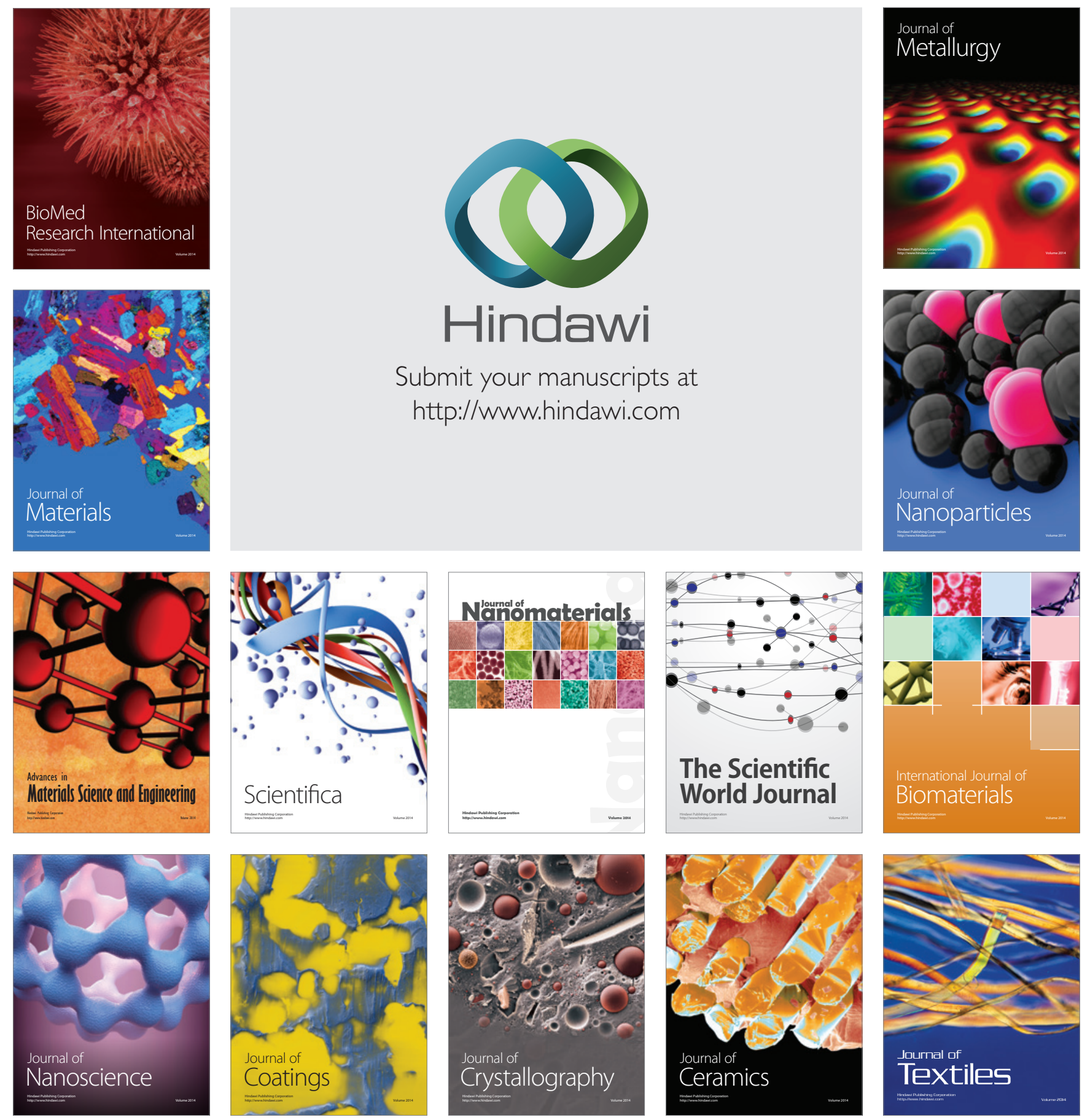